Original Article

\title{
Dynamic Smile Visualization and Quantification in different age groups
}

\author{
Harshitha V. ${ }^{1}$, M.S. Ravi', Reshma Raveendran ${ }^{3}$, Raed Saeed ${ }^{4}$, Kiran Kumar C. ${ }^{5}$ \\ ${ }_{1,3}^{1,3}$ Senior Lecturer, ${ }^{2}$ Professor, ${ }^{4}$ Post Graduate, ${ }^{5}$ Former Lecturer, Dept. of Orthodontics and Dentofacial Orthopaedics, A.B. \\ Shetty M emorial Institute of Dental Sciences, Deralakatte, Mangalore - 575 018, India.
}

*Corresponding Author : M.S. Ravi, Professor, Dept. of Orthodontics and Dentofacial Orthopedics, A.B. Shetty M emorial Institute of Dental Sciences, Deralakatte, Mangalore - 575018 , India.

$\begin{array}{ll}\text { Received } & : 06.06 .2016 \\ \text { Review Completed } & : 27.08 .2016 \\ \text { Accepted } & : 15.10 .2016\end{array}$

Keywords : Digital video clips, Dynamic smile, Posed smile, Smile analysis, Different age groups.

\begin{tabular}{|c|}
\hline Access this article online \\
\hline Quick Response Code \\
\hline
\end{tabular}

\begin{abstract}
Aims and Objectives: To assess the posed and dynamic smile and to compare the various attributes of smile in frontal, oblique and sagittal dimensions, in two different age groups (1015years and 18-25 years).
\end{abstract}

M aterials and method : The posed and dynamic smile parameters were measured using digital video clips in 80 subjects of two different age groups (10-15years and 18-25 years). Total of 15 parameters were studied in 3 planes of space. The data was analysed using student's t-test to compare smile parameters across the age groups, paired t-test was used to analyse the parameters of posed and unposed smile within the same age group and chi-square test was performed for the discrete data.

Results : The present study revealed significant differences in dynamic smile parameters between the two age groups. The parameters like Philtrum height and Smile index are more in older age group whereas the buccal corridor was more in younger age group. Significant differences were also recorded in various parameters in both the groups when the posted smile is compared with that of the dynamic smile.

Conclusion : In both the age groups, the dynamic and posed smile attributes are significantly different, except for buccal corridor and interlabial gap.

\section{Introduction}

Nature has endowed every individual with a definite pattern of smile. A Smile, when pleasing and attractive, enriches not only the one who smiles, but also the observers of it. The clinicians ability to understand the positive elements in beautifying individual patient's smile and creating different strategies increases the aesthetic attributes that lies outside the general aesthetic concept. The latest advances in different fields have significantly improved our ability to view our patients in a more dynamic way and helped us to improve the quantification and communication of newer concepts of function and apperanance. Today, the orthodontist's ability to clinically evaluate the patient in 3 dimension and use the latest technologies (Computer data basing of the clinical examination and digital videography) to document, define and communicate the treatment strategy to patients and collegues involved in interdisciplinary care leads to the concept of "art of smile". ${ }^{1}$

The orthodontist has an all important role in establishing a pleasant smile through his clinical skill and knowledge in various treatment procedures. Orthodontic speciality is presently focussing its attention on the multifactorial nature of smile, combined with a shift towards patientdriven aesthetic diagnosis and problem oriented treatment planning. ${ }^{2}$

Therefore this study was carried out with the objective of assessing the posed and dynamic smile and to compare the various attributes of smile in frontal, oblique and sagittal dimensions, in two different age groups

The results of this study would help the orthodontist in establishing a better diagnosis identifyingthe various attributes of smile that needs correction, improvement or enhancement and to identify if the attribute contributes 
positively or negatively in designing the smile of a patient. An attractive, well balanced smile is a paramount treatment objective of modern orthodontics. ${ }^{1}$

\section{Materials and Methods}

A total of 80 subjects were selected to measure the liptooth characteristics in the $10-15$ years and $18-25$ years age group. Thus it was imperative to select a sample containing a uniform proportion of girls (20 in each group) and boys (20 in each group) spanning cross both the age groups. The subjects selected had class I skeletal pattern with near normal dental occlusion. None of the subjects had undergone prior orthodontic/surgical treatments

\section{Method of collection of Data}

To capture a patient's speech, oral and pharyngeal function and smile at the same time, the best method would be standardised digital videography. ${ }^{3}$ The patient was seated in a cephalostat and placed in natural head position. Ear rods were used to stabilize the head and avoid excess motion. The digital video camera Cannon Powershot A630 was mounted on a camera tripod stand and set at a fixed distance of $2.5 \mathrm{ft}$ from the patient. The lens of the camera was positioned parallel to the true perpendicular of the face in natural head position, and the camera was raised to the level of the patient's lower facial third and the patient was asked to relaxand then smile.

Pictures were made from the oblique and sagittal view and video was made in the frontal dimension. The tooth display varies during speech and smiles. So all aspects of anterior tooth display was evaluated by a video clip during speech and smiling at the equivalent of 30 frames per second; Each subjects had 5 seconds of video yielding 150 frames for comparison.

The raw clip was downloaded to Windows M ovie M aker for reviewing and selecting the frame that best represents the patient's natural unstrained social smile. (Refer Figure - 1)

\section{Smile Analysis}

The photo was selected that best represented the subject's social smile then captured using a program called Windows M ovie M aker and saved as aJPEG file. The smile image was then measured for the fifteen attributes using Adobe Photoshop CS2 version 9.0, scaling and measuring grid (Refer Figure- 2 and figure - 4) and M S- Excel.

Still pictures (Fig - 3) were also made to measure the various attributes of posed smile. 15attributes of smile in 3 dimensions were measured (table: 1 ):

The data thus obtained was subjected to statistical analysis using student's t-test to compare smile parameters across the age groups. This method of analysis assumes that the data are symmetrically distributed around the mean and that the standard error of each sample was approximately the same. Chi-square test was performed for discrete data.

\section{Results}

The present study has analyzed fifteen different parameters of posed and dynamic smile of 80 individuals of two different age groups, 10-15years and 18-25years with class I skeletal base. Data analysed using student's t-test and Chi square test revealed the following information:

- Means and standard deviations (SD) for each of the measurements during dynamic (during chee articulation) and posed social smile were calculated. (table 2)

- The parameters significantly different during the testing of hypothesis for means of dynamic smile parameters between the age groups $10-15$ years and $18-25$ years are Philtrum height, Buccal Corridor and Smile Index $(p=0$, 0.003 and 0.004 respectively).The parameters not significantly different are Commissure height, Interlabial gap, M axillary incisor show, Crown height and Gingival display $(p=0.298,0.233,0.513,0.804$ and 0.2 respectively). (table 3 )

- Chi square test revealed no statistically significant values. The most prevalent parameters for both age groups were: The consonant smile arc in both, frontal and oblique dimension, Broad arch form, Symmetrical transverse cant of maxillary occlusal plane, Consonant orientation of palatal plane, Normal overjet and Upright incisor angulation (Table 4). 


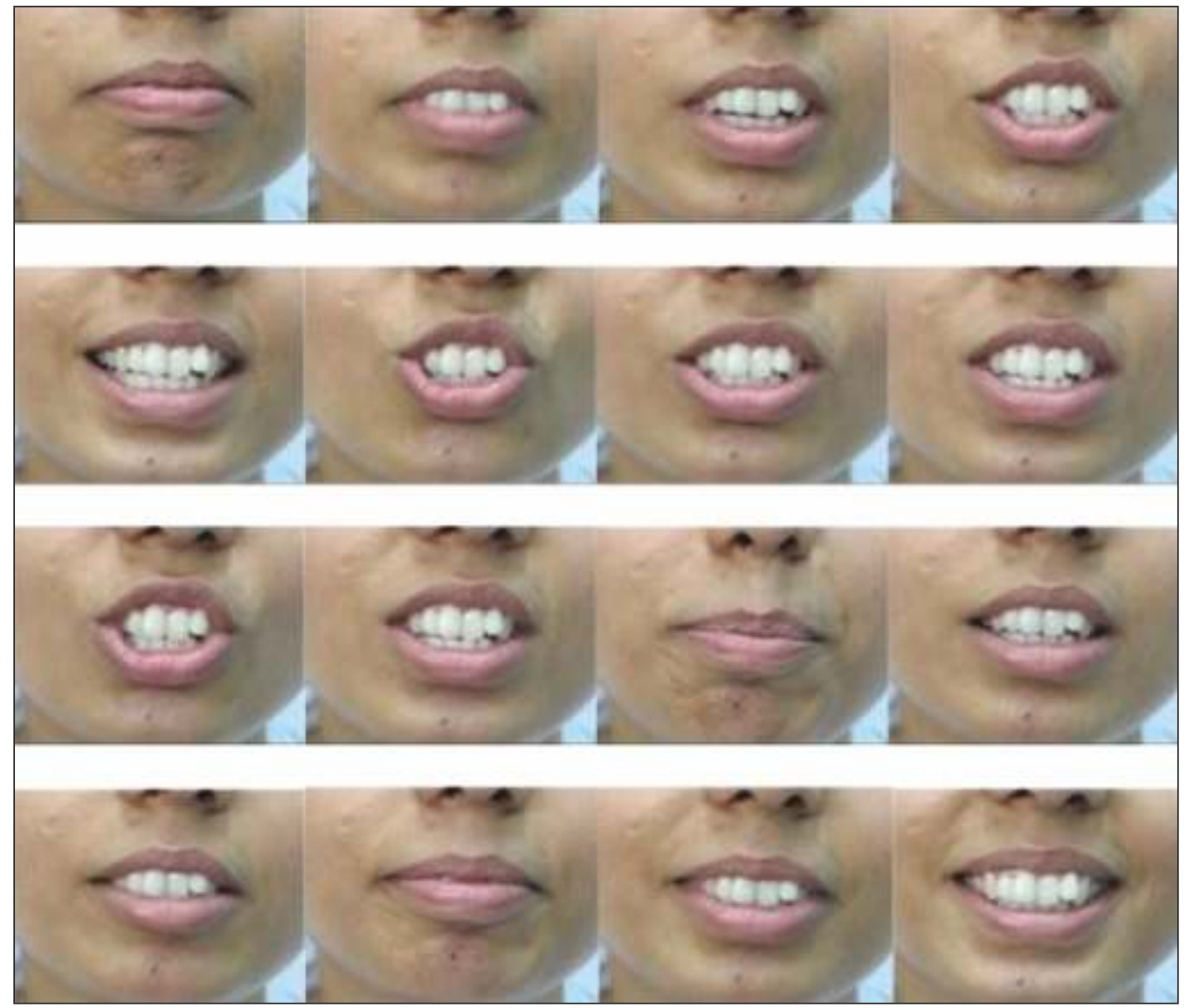

Figure 1 : Dynamic frames from patient's video clip

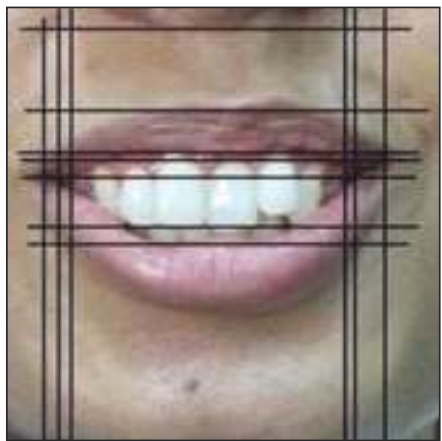

Figure 2 : Smile grid applied to patient's dynamic smile

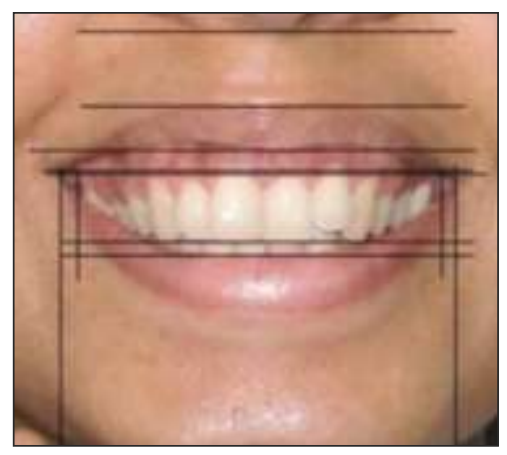

Figure 4 : Smile grid applied to patient's social smile Oblique Photograph

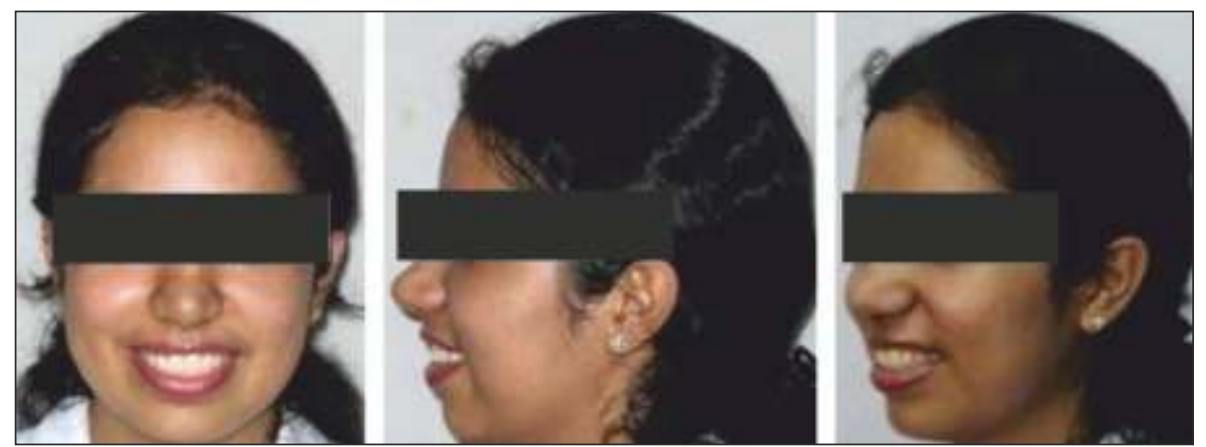

Figure 2 : Still pictures of patient in the order: Frontal Photograph, Profile Photograph and

\section{Results}

The present study has analyzed fifteen different parameters of posed and dynamic smile of 80 individuals of two different age groups, 10-15years and 18-25years with class I skeletal base. Data analysed using student's t-test and Chi square test revealed the following information:

- Means and standard deviations (SD) for each of the measurements during dynamic (during chee articulation) and posed social smile were calculated. (table 2) 
Table 1 : Attributes of smile parameters in the study

\begin{tabular}{|c|c|c|c|c|c|c|c|c|c|}
\hline ATTRIBUTES & SMILE & AGE & $\mathbf{N}$ & MAX. & MEAN & SE MEAN & MEDIAN & SD & MIN. \\
\hline \multirow[t]{4}{*}{ PHILTRUM HEIGHT } & \multirow[t]{2}{*}{ Dynamic } & $10-15$ & 40 & 17.33 & 9.79 & 0.39 & 8.81 & 2.49 & 6.27 \\
\hline & & $18-25$ & 40 & 22.61 & 12.27 & 0.44 & 11.90 & 2.80 & 8.50 \\
\hline & \multirow[t]{2}{*}{ Posed } & $10-15$ & 40 & 12.36 & 8.40 & 0.38 & 8.23 & 2.38 & 2.72 \\
\hline & & $18-25$ & 40 & 14.80 & 9.40 & 0.36 & 8.87 & 2.29 & 5.56 \\
\hline \multirow[t]{4}{*}{ COMMISSURE HEIGHT } & \multirow[t]{2}{*}{ Dynamic } & $10-15$ & 40 & 31.10 & 22.27 & 0.53 & 21.87 & 3.38 & 16.50 \\
\hline & & $18-25$ & 40 & 35.61 & 22.79 & 0.62 & 21.72 & 3.89 & 15.79 \\
\hline & \multirow[t]{2}{*}{ Posed } & $10-15$ & 40 & 22.67 & 15.79 & 0.58 & 16.15 & 3.67 & 7.06 \\
\hline & & $18-25$ & 40 & 24.12 & 16.37 & 0.50 & 16.13 & 3.15 & 12.14 \\
\hline \multirow[t]{4}{*}{ INTER LABIAL GAP } & \multirow[t]{2}{*}{ Dynamic } & $10-15$ & 40 & 13.90 & 9.71 & 0.33 & 9.00 & 2.11 & 6.00 \\
\hline & & $18-25$ & 40 & 15.42 & 9.30 & 0.44 & 9.15 & 2.76 & 5.40 \\
\hline & \multirow[t]{2}{*}{ Posed } & $10-15$ & 40 & 12.67 & 8.49 & 0.39 & 8.76 & 2.48 & 3.37 \\
\hline & & $18-25$ & 40 & 17.72 & 8.93 & 0.49 & 8.36 & 3.13 & 3.93 \\
\hline \multirow{4}{*}{$\begin{array}{l}\text { MAXILARY INCISSOR } \\
\text { SHOW }\end{array}$} & \multirow[t]{2}{*}{ Dynamic } & $10-15$ & 40 & 9.41 & 6.06 & 0.28 & 6.20 & 1.78 & 2.87 \\
\hline & & $18-25$ & 40 & 10.80 & 6.01 & 0.36 & 5.31 & 2.29 & 1.70 \\
\hline & \multirow[t]{2}{*}{ Posed } & $10-15$ & 40 & 10.82 & 7.14 & 0.31 & 7.09 & 1.98 & 3.26 \\
\hline & & $18-25$ & 40 & 11.82 & 7.39 & 0.31 & 7.64 & 1.93 & 3.32 \\
\hline \multirow[t]{4}{*}{ CROWN HEIGHT } & \multirow[t]{2}{*}{ Dynamic } & $10-15$ & 40 & 9.41 & 6.37 & 0.30 & 6.20 & 1.92 & 2.87 \\
\hline & & $18-25$ & 40 & 10.92 & 6.49 & 0.35 & 5.60 & 2.22 & 1.70 \\
\hline & \multirow[t]{2}{*}{ Posed } & $10-15$ & 40 & 11.05 & 7.88 & 0.32 & 8.30 & 1.99 & 3.48 \\
\hline & & $18-25$ & 40 & 11.82 & 8.24 & 0.26 & 8.36 & 1.65 & 5.00 \\
\hline \multirow[t]{4}{*}{ GINGIVAL DISPLAY } & \multirow[t]{2}{*}{ Dynamic } & $10-15$ & 40 & 0.50 & 0.03 & 0.02 & 0 & 0.11 & 0 \\
\hline & & $18-25$ & 40 & 10.92 & 6.49 & 0.35 & 5.60 & 2.22 & 1.70 \\
\hline & \multirow[t]{2}{*}{ Posed } & $10-15$ & 40 & 1.55 & 0.15 & 0.06 & 0 & 0.39 & 0 \\
\hline & & $18-25$ & 40 & 3.94 & 0.55 & 0.17 & 0 & 1.08 & 0 \\
\hline \multirow[t]{4}{*}{ BUCCAL CORRIDOR } & \multirow[t]{2}{*}{ Dynamic } & $10-15$ & 40 & 7.41 & 4.70 & 0.24 & 4.82 & 1.51 & 0 \\
\hline & & $18-25$ & 40 & 6.10 & 3.78 & 0.18 & 3.67 & 1.14 & 0.68 \\
\hline & \multirow[t]{2}{*}{ Posed } & $10-15$ & 40 & 8.30 & 3.87 & 0.27 & 3.56 & 1.70 & 1.41 \\
\hline & & $18-25$ & 40 & 11.18 & 4.05 & 0.42 & 3.53 & 2.68 & 0 \\
\hline \multirow[t]{4}{*}{ SMILE INDEX } & \multirow[t]{2}{*}{ Dynamic } & $10-15$ & 40 & 7.83 & 5.38 & 0.17 & 5.38 & 1.10 & 3.38 \\
\hline & & $18-25$ & 40 & 6.10 & 3.78 & 0.18 & 3.67 & 1.14 & 0.68 \\
\hline & \multirow[t]{2}{*}{ Posed } & $10-15$ & 40 & 17.8 & 7.43 & 0.46 & 6.44 & 2.93 & 5.11 \\
\hline & & $18-25$ & 40 & 15.15 & 7.44 & 0.38 & 7.01 & 2.39 & 3.61 \\
\hline
\end{tabular}

Table 2 : Summary of Descriptive Statistics of Smile across age groups

\begin{tabular}{|c|c|c|}
\hline S.NO & PARAMETER & MEASURM ENTS \\
\hline 1. & PHILTRUM HEIGHT & $\begin{array}{l}\text { Measured from Subspinale to the most inferior portion of the upper lip on the } \\
\text { vermilion tip beneath thephilitral columns }\end{array}$ \\
\hline 2. & COM MISSUREHEIGHT & $\begin{array}{l}\text { Measured from a line constructed from the alar bases through the subspinale and } \\
\text { then from the commissuresperpendicular to thisline }\end{array}$ \\
\hline 3. & INTERLABIALGAP & Distance between the upper and lower lips when lip incompetence is present \\
\hline 4. & MAXILLARYINCISORSHOW & The amount of maxillary incisors exposed vertically on smiling \\
\hline 5. & CROWN HEIGHT & Vertical height of the maxillary central incisors \\
\hline 6. & GINGIVALDISPLAY & Amount of gingival exposures vertically \\
\hline 7. & SMILEARC & $\begin{array}{l}\text { Relationship of the curvature of the incisal edges of the maxillary incisors and canines } \\
\text { to the curvature of the lower lip in the posed social smile }\end{array}$ \\
\hline 8. & ARCHFORM & Shape of the arch - broad, narrow or normal \\
\hline 9. & BUCCALCORRIDOR & $\begin{array}{l}\text { M easured from the mesial line angle of the maxillary first premolars to the interior } \\
\text { portion of the commissure of the lips }\end{array}$ \\
\hline 10. & $\begin{array}{l}\text { TRANSVERSE CANTOF } \\
\text { MAXILLARY OCCLUSALPLANE }\end{array}$ & Symmetrical or assymetrical \\
\hline 11. & ORIENTATION OF PALATAL PLANE & $\begin{array}{l}\text { Downward cant of the posterior maxilla, upward cant of the anterior maxilla or } \\
\text { variations of both. It can be consonant or non consonant }\end{array}$ \\
\hline
\end{tabular}




\begin{tabular}{|c|l|l|}
\hline S.NO & PARAMETER & MEASURM ENTS \\
\hline 12. & SMILEARC & $\begin{array}{l}\text { Relationship of the curvature of the incisal edges of the maxillary incisors, canines, } \\
\text { premolars and molars to the curvature of the lower lip in posed smile. This can be }\end{array}$ \\
\hline 13. & OVERJET & $\begin{array}{l}\text { consonant, non-consonant or a reverse smile arc. } \\
\text { Normal }(2-4 \mathrm{~mm}), \text { positive }(>4 \mathrm{~mm}) \text { or negative }(<\mathrm{mm})\end{array}$ \\
\hline 14. & INCISOR ANGULATION & Upright, proclined, Retroclined \\
\hline 15. & SM ILEINDEX & Determined by dividing the inter commissure width by the interlabial gap during smile. \\
\hline
\end{tabular}

$\mathrm{SE}=$ Standard error mean

$\mathrm{SD}=$ Standard deviation

Table 3 : Hypothesis testing for means of Dynamic Smile parameters between age groups 10-15 years and 18-25 years

\begin{tabular}{|l|c|c|c|l|}
\hline Parameter & $\mathbf{1 0}$ to $\mathbf{1 5}$ years & $\mathbf{1 8}$ to $\mathbf{2 5}$ years & $\begin{array}{c}\text { T- test } \\
\text { P-value }\end{array}$ & $\begin{array}{l}\text { Significance } \\
\text { of Difference }\end{array}$ \\
\hline Philtrum Height & $9.78+/-3 \times 2.50$ & $12.27+/-3 \times 2.80$ & 0 & significantly different \\
\hline Commisure Height & $22.27+/-3 \times 3.37$ & $22.79+/-3 \times 3.89$ & 0.298 & Not significantly different \\
\hline Inter-labial Gap & $9.7+/-3 \times 2.10$ & $9.30+/-3 \times 2.76$ & 0.233 & Not significantly different \\
\hline Maxillary Incisor show & $6.06+/-3 \times 1.78$ & $6.01+/-3 \times 2.29$ & 0.513 & Not significantly different \\
\hline Crown height & $6.36+/-3 \times 1.92$ & $6.5+/-3 \times 2.22$ & 0.804 & Not significantly different \\
\hline Gingival display & $0.03+/-3 \times 0.11$ & $0.09+/-3 \times 0.27$ & 0.2 & Not significantly different \\
\hline Buccal Corrider & $4.7+/-3 \times 1.51$ & $3.78+/-3 \times 1.15$ & 0.003 & significantly different \\
\hline Smile Index & $5.37+/-3 \times 1.10$ & $6.12+/-3 \times 1.65$ & 0.004 & significantly different \\
\hline
\end{tabular}

Table 4 : Hypothesis testing for means of Discrete Dynamic Smile Parameters between age groups

\begin{tabular}{|l|c|l|}
\hline Parameter & $\begin{array}{c}\text { Chi-Sq test } \\
\text { P-value }\end{array}$ & Significance of Difference \\
\hline Frontal Smile Arc & 0.8303 & Not significantly different \\
\hline Frontal Arch form & 0.152 & Not significantly different \\
\hline Frontal Transverse Cant & NA & No difference \\
\hline Orientation of Palatal Plane & 0.358 & Not significantly different \\
\hline Oblique-Smile Arc & 0.833 & Not significantly different \\
\hline Overjet & 0.34 & Not significantly different \\
\hline IncisorAngulation & 0.34 & Not significantly different \\
\hline
\end{tabular}

- The parameters significantly different during the testing of hypothesis for means of dynamic smile parameters between the age groups $10-15$ years and $18-25$ years are Philtrum height, Buccal Corridor and Smile Index $(p=0$, 0.003 and 0.004 respectively).The parameters not significantly different are Commissure height, Interlabial gap, M axillary incisor show, Crown height and Gingival display $(p=0.298,0.233,0.513,0.804$ and 0.2 respectively). (table 3 )

- Chi square test revealed no statistically significant values. The most prevalent parameters for both age groups were: The consonant smile arc in both, frontal and oblique dimension, Broad arch form, Symmetrical transverse cant of maxillary occlusal plane, Consonant orientation of palatal plane, Normal overjet and Upright incisor angulation (Table 4).

\section{Discussion}

Generally a smile is considered as a friendly greeting in all cultures. In modern society an attractive smile is often considered as an asset in interviews, work settings, social interactions, and even the quest to attract a mate. Nowadays smile is given much importance and there is increasing emphasis on aesthetic by our society. But a perusal of the dental and orthodontic literature shows that there is much conjecture about "smile design" and treatment for smile aesthetics, sound scientific data are actually quite sparse. ${ }^{3}$

Recent studies described a new method of capturing and analysing the smile with videography and computer software compared to the older scientific studies which examined smile aesthetics using static photographs. The credit for the use of videography to analyse smiles with 
videography goes to Ackerman et al, Ackerman and Ackerman, and Sarver and Ackerman. We can achieve a much more predictable and standardised smile using a video (about 30 frames per second) than by static photographs and with the use of computer software to analyse and measure smile we are able to extract the frame that best represents patients social smile andthe errors in measurements can be reduced to a great extent. Analyzing the smile and obtaining averages for various components can shed light on a standard of normalcy to serve as a guideline for the creation of an aesthetic smile. ${ }^{1,4,5,6,7}$.

Clinically and statistically significant changes in anterior liptooth relationships were found between speech and smile. Soft tissue dimensional changes occur between saying "Chee" and the posed social smile. The commissures of the lips move significantly more superiorly and laterally in the posed social smile. Hence, the spatial change at the commissures directly affects the amount of percent incisor below the intercommissure line, and the increase in smile width will proportionately increase smile index. Two dimensionally and morphologically different lip frameworks are present in the "Chee" articulation and the posed social smile. When compared with single frame capture method with digital photography, standardized digital videography provides the clinician a wider range of images for selecting the parameters of lip-tooth relationships during facial animation. Because there is variability in the posed social smile in adolescents with time, a single digital photography is insufficient for the evaluation of treatment effects or maturational changes. ${ }^{8}$

The present study analyzed fifteen different parameters of dynamic and posed smile of 80 individuals of two different age groups, 10-15 years and 18-25 years with class I Skeletal base and no gross deformities. Male and female distribution in each group was equal (20 each).The parameters were analyzed in all the three dimensions.

Digital video clips of the 80 subjects in the frontal dimension and pictures of the same patients in the frontal, oblique and sagittal dimension were taken and analyzed based on the above mentioned parameters.
The various attributes of dynamic smile were compared for the two age groups.

Statistical analysis indicated the following results:

- Philtrum height:When compared between the two age groups the philtrum height during dynamic smile for 10 15years age group was lesser than the 18-25 years age group (Table 2). Review of literature did not reveal any previous studies comparing the philtrum heights.

- Commissure height : When compared between the two age groups the commissure height during dynamic smile was almost the same for both age groups (Table 2). Commissure height has also not been addressed by any previousstudies.

- Inter-labial gap: When compared between the two age groups the interlabial gap during dynamic smile was almost the same for both age groups (Table 2).

- Maxillary incisor show: When compared between the two age groups the maxillary incisor show during dynamic smile was almost the same for both age groups (Table 2).

- Crown height: When compared between the two age groups the Crown height during dynamic smile was almost the same for both age groups (Table 2 ) which is not in accordance with the study done by Gillen RJ etal, which depicts thatthe age of the patient is a factor in crown height as a cause of the apical migration in the adolescence. $^{9}$

- Gingival display: When compared between the two age groups the gingival display during dynamic smile was almost the same for both age groups (Table 2 ) which is not in accordance to the study done by Sarver DM, Ackerman $M B{ }^{1}$ which says that aging will diminish gingival display.

- Buccal corridor: When compared between the two age groups the buccal corridor during dynamic smile was greater for the 10-15 years age group (Table 2).

- Smile index: When compared between the two age groups the smile index during dynamic smile was greater for the 18-25 years age group (Table 2 ) which is 
in accordance to the study done by Sarver DM, Ackerman MB. ${ }^{1}$ It is said that, as the smile index decreases the less youthful the smile appears.

- Smile arc: Consonant smile arc was the most common both frontally and obliquely in both age groups. It is well known that compared to a non-consonant smile, a consonant smile arc is more attractive. ${ }^{7,10}$ Orthodontists should try not to disturb consonant smiles but create them by accurate and precise bracket positions.

- Arch form: As viewed frontally, Broad arch form was the most common in both age groups.

- Transverse cant of maxillary occlusal plane: Symmetrical cant was observed in all the subjects.

- Orientation of palatal plane: Consonant palatal plane was the most common followed by the non-consonant plane with upward cant of anterior maxilla, next followed by non-consonant plane with downward cant of posterior maxilla in both age groups.

- Over jet:Over jet was normal in majority of the subjects in both age groups.

- Incisor angulation: Upright incisor was the most common in both age groups.

\section{References}

1. Sarver DM, Ackerman MB. Dynamic smile visualization and quantification: Part 1.Evolution of the concept and dynamic records for smile capture. Am J Orthod Dentofacial Orthop 2003; 124:4-12.

2. Sarvera, David M., James L. Ackermanb. Orthodontics about face: the re-emergence of the aesthetic paradigm. Am J Orthod Dentofacial Orthop 2000;117:575-6.

3. C Maulik, R Nanda. Dynamicsmileanalysis in young adults. AmJ Orthod Dentofacial Orthop 2007;132:3:307-15

4. Ackerman MB, Ackerman JL. Smile analysis and design in the digital era. J. Clin. Orthod 2002;36:221-36.

5. Tjan AHL, Miller GD. Some aesthetic factors in smile. J. Prosthet .Dent 1984;51(1):24-8.

6. Peck S, Peck L, Kataja M. The gingival smile line. Angle Orthod 1992;62: 91-100.

7. Sarver DM, Ackerman M. Dynamic smile visualization and quantification: Part 2. Smile analysis and treatment strategies. Am J Orthod Dentofacial Orthop 2003; 124:116-27.

8. Ackerman MB, Colleen Brensinger, Richard Landis. An Evaluation of Dynamic Lip-Tooth Characteristics During Speech and Smile in Adolescents. The Angle Orthodontist 2003; 74(1): 43-50.

9. Gillen RJ, Schwartz RS, Hilton TJ, Evans DB. An analysis of selected normative tooth proportions. Int J Prosthodont 1994; 7:410-17.

10. Sarver D. The importance of incisor positioning in the aesthetic smile: the smile arc. Am J Orthod Dentofacial Orthop 2001; 120:98-111.
Therefore, the results of this study shows that the maturation and aging has significant effect on the soft tissues as this can be observed with decrease in incisor and gingival display at rest and during smile, decrease in turgor (or tissue "fleshiness"), and also the lengthening of the resting commissure and philtrum heights,

These changes need to be kept in mind during diagnosis and treatment planning with orthodontic mechanics in different age group of individuals.

\section{Conclusion}

This study helps us to establish that dynamic smile parameters like Smile Index and philtrum height increase from adolescents to adults whereas buccal corridor shows a decrease with age.This study depicts that dynamic smile parameters are different in adolescents (10-15 years age group) and adults (18-25 years age group) which may be due to growth, maturation and ageing.

This study also shows that dynamic smile visualization is a better method of studying smile rather than still pictures to enhance facial aesthetics.Further studies are required to assess the soft tissue parameters in different age groups and also in different ethnic group. 